\title{
Molecular Characterization of Naturally Occurring RNA1 Recombinants of the Comovirus Bean pod mottle virus
}

\author{
Chunquan Zhang, Hongcang Gu, and Said A. Ghabrial
}

Department of Plant Pathology, University of Kentucky, 201F Plant Science Building, 1405 Veterans Drive, Lexington 40546. Accepted for publication 30 April 2007.

\begin{abstract}
Zhang, C., Gu, H., and Ghabrial, S. A. 2007. Molecular characterization of naturally occurring RNA1 recombinants of the comovirus Bean pod mottle virus. Phytopathology 97:1255-1262.

The Bean pod mottle virus, a member of the genus Comovirus, has a bipartite genome consisting of RNA1 and RNA2. We previously reported the occurrence in nature of two distinct subgroups of BPMV strains (subgroups I and II), as well as reassortants between the two subgroups. Here, we report on the isolation and molecular characterization of RNA1 recombinants from soybean plants infected with the partial diploid reassortant strain IL-Cb1, which induces very severe symptoms on soybean. cDNA cloning and sequencing of RNA1 from strain IL-Cb1 revealed the

presence of chimeric and mosaic recombinant RNA1s. The full-length mosaic and chimeric recombinant RNA1s were infectious and induced mild symptoms on soybean. Although the recombinant RNA1 accumulated to high levels in the absence of wild-type RNA1, its accumulation level was low in mixed infections with wild-type RNA1. Recombinant RNA1 molecules with similar structures to the naturally occurring recombinant RNA1s were generated in soybean after four passages following inoculation with RNA1 transcripts derived from cDNAs of two distinct strains. This suggests that recombination events are frequent and that a recombination hot spot exists. Sequence analysis of the recombination region showed that it has AU-rich sequences characteristic of recombination hot spots.
\end{abstract}

Viral RNA recombination, a major driving force for virus evolution, is a process that links together two noncontiguous RNA regions to produce a new RNA containing genetic information from more than one source $(6,23)$. Since the first report of RNA recombination in a plant RNA virus (Brome mosaic virus; 3), evidence has been accumulating for RNA recombination events in a number of other plant RNA viruses. The availability and abundance of viral genomic sequences make it possible to predict viral RNA recombination based on phylogenetic analysis. Another approach is based on experimental recovery of recombinants from known parental populations. Although many viral RNA recombination events are implied by phylogenetic analysis $(2,10,11$, $25,26)$, examples of experimentally confirmed plant viral RNA recombination are limited to a few viral genera belonging to the families Bromoviridae, Comoviridae, Luteoviridae, Potyviridae, and Tombusviridae $(1,4,5,15,20,27,29)$.

Bean pod mottle virus (BPMV), a major soybean pathogen, is a member of the genus Comovirus in the family Comoviridae (16). BPMV has a bipartite positive-strand RNA genome consisting of RNA1 (approximately $6.0 \mathrm{~kb}$ ) and RNA2 (approximately $3.6 \mathrm{~kb}$ ) that are separately encapsidated in isometric particles $28 \mathrm{~nm}$ in diameter. The genomic RNAs have a small basic protein (viral genome-linked protein, $\mathrm{VPg}$ ) covalently linked to their $5^{\prime}$ termini and are polyadenylated at the $3^{\prime}$ end. The BPMV genome is expressed via the synthesis and proteolytic processing of polyprotein precursor strategy. BPMV RNA1 codes for five mature proteins required for replication (from $5^{\prime}$ to $3^{\prime}$, a protease cofactor [Co-pro], a putative helicase [Hel], a VPg, a protease [Pro], and a putative RNA-dependent RNA polymerase [RdRp]), whereas

Corresponding author: S. A. Ghabrial; E-mail address: saghab00@email.uky.edu

* The $\boldsymbol{e}$-Xtra logo stands for "electronic extra" and indicates that the online version contains supplemental material not included in the print edition. Figures 1 and 5 appear in color online.

doi:10.1094/PHYTO-97-10-1255

(C) 2007 The American Phytopathological Society
RNA2 codes for a putative cell-to-cell movement protein and the two coat proteins $(16,17)$.

BPMV is widespread in the major soybean-growing areas in the United States. BPMV strain K-G7, the type strain of BPMV, was the first strain to be well characterized biologically, structurally, and at the molecular level $(7,9,12-14)$. To facilitate the classification of BPMV isolates based on nucleic acid hybridization analysis, strain K-G7 was previously designated as the prototype of hybridization subgroup I (13). Strain K-Ha1, which does not hybridize with the K-G7 cDNA probes, was designated as the prototype of a second strain subgroup (subgroup II). The percent nucleotide sequence identity scores between strains K-G7 and KHa1 are 83.6 and $84.4 \%$, respectively, for RNA1 and RNA2. The BPMV strain subgroups I and II can thus be clearly differentiated based on nucleic acid hybridization and nucleotide sequencing analyses (13). Naturally occurring haploid and partial diploid reassortants between the two subgroups have also been described (12-14; this study). The complete nucleotide sequences of the two genomic RNAs of several BPMV strains have been determined $(7,12-14,18)$. In this study, RNA recombinants were isolated from the BPMV natural reassortant IL-Cb1 and characterized at the molecular level. Similar recombinants were also recovered from an artificial viral population generated by coinfection with subgroup I and II strains. To our knowledge, this is the first report of a naturally occurring RNA recombinant for a member in the genus Comovirus.

\section{MATERIALS AND METHODS}

Virus isolation and propagation. BPMV strain IL-Cb1, a partial diploid reassortant strain (14) originally collected from a soybean field in Carbondale, IL, was maintained in the greenhouse in soybean cv. Essex. Virion purification from infected leaf tissues was carried out as previously described (9). Strains K-G7, $\mathrm{K}-\mathrm{Ha} 1$, and K-Ho1 were previously described $(12,13)$.

Local lesion isolation. BPMV strain IL-Cb1 was passaged through two consecutive local lesion transfers on Phaseolus 
vulgaris cv. Pinto. A dilute inoculum was prepared from IL-Cb1 systemically infected soybean leaves (equivalent to $100 \mathrm{mg}$ of leaf tissue in $10 \mathrm{ml}$ of $0.05 \mathrm{M}$ potassium phosphate buffer, $\mathrm{pH}$ 7.0) and used to inoculate 16 Pinto bean leaves by rub inoculation. A total of 16 single lesions were selected, one from each of the 16 leaves, and used to inoculate a new set of 16 Pinto bean leaves. One lesion from each of the second set of 16 Pinto bean leaves was then used to inoculate soybean seedlings. Each lesion was rubbed onto a single soybean plant.

RNA extraction and northern blot hybridization. Viral RNA was extracted from purified virions by the sodium dodecyl sulfate-phenol method (22). Northern blot hybridization analysis was performed using cloned cDNA probes to full-length RNA1(I) from strain K-Ho1 and RNA1(II) from strain K-Ha1. Purified virion RNAs were separated by electrophoresis on $0.8 \%$ glyoxal gel (24) and transferred onto Hybond- $\mathrm{N}^{+}$membranes (Amersham Pharmacia Biotech, Piscataway, NJ), according to the manufacturer's instructions. The membranes were then prehybridized, hybridized, and air-dried according to $\mathrm{Gu}$ et al. (13). The probes were prepared by the Rediprime II random prime labeling system (Amersham Pharmacia Biotech). The membranes were exposed to a phosphorimager screen (Molecular Dynamics, Sunnyvale, CA) for 12 to $24 \mathrm{~h}$. The images were visualized with a PhosphorImager 445 SI system and analyzed with the ImageQuant 4.1 program (Molecular Dynamics).

cDNA synthesis and cloning. Viral RNA was extracted from purified virions of strain IL-Cb1, and RNAs 1 and 2 were purified from low-melting agarose following electrophoretic separation. cDNA synthesis was carried out by the SuperScript choice system (Invitrogen, Carlsbad, CA) according to the manufacturer's instructions. First-strand cDNA synthesis was primed with oligo $(\mathrm{dT})_{12-18}$ primers. Following addition of EcoRI adapters to the ends of the double-stranded cDNA, it was ligated into EcoRIlinearized pGEM $3 \mathrm{ZF}(+)$ vector (Promega, Madison, WI). For cloning the viral genomic RNA 5' end, the 5'-rapid amplification of cDNA ends (RACE) system (Invitrogen) was used and the final PCR product was cloned into the pGEM-T easy vector (Promega).

Construction of full-length cDNA clones. For cloning fulllength IL-Cb1 RNA2, two IL-Cb1 RNA2 cDNA clones, IL-Cb1609 and IL-Cb1-128 (both cloned in pGEM 3ZF(+) using the SuperScript choice system), were selected and digested with EcoRV. The 5' end region of clone IL-Cb1-609 (5 kbp containing the vector backbone) and the $3^{\prime}$ end region of clone IL-Cb1-128 $(1.6 \mathrm{kbp})$ were gel purified and ligated using T4 ligase. The ligation product was used as a template for PCR amplification with primers F1 and R1 (Table 1). The PCR product was cloned into the pGEM-T easy vector and used for in vitro transcription.

Full-length cDNA clones of RNA1(I) and RNA1(II) as well as the recombinant RNA1s were constructed using an reverse transcription-polymerase chain reaction (RT-PCR) strategy. RNA1 3' end-specific primer, R1-Rev1 (Table 1), was used for first-strand cDNA synthesis with the SuperScript II system (Invitrogen). Briefly, $4 \mu \mathrm{g}$ of viral RNA and $20 \mathrm{pM}$ primer were mixed together to a final volume of $11 \mu \mathrm{l}$. The mixture was first incubated at $70^{\circ} \mathrm{C}$ for $10 \mathrm{~min}$ and at $37^{\circ} \mathrm{C}$ for $20 \mathrm{~min}$. After incubation, $4 \mu \mathrm{l}$ of $5 \times$ first-strand buffer, $2 \mu \mathrm{l}$ of $0.1 \mathrm{M}$ DTT, $1 \mu \mathrm{l}$ of dNTP, and $2 \mu \mathrm{l}$ of SuperScript II enzyme were added. The reaction was incubated at $37^{\circ} \mathrm{C}$ for $90 \mathrm{~min}$, and the product was subjected to PCR. PCR was performed using Platinum High Fidelity Taq DNA Polymerase (Invitrogen) and different combinations of the primers shown in Table 1 . Thermal cycling conditions for amplifying the $5^{\prime}$ end region were as follows: $94^{\circ} \mathrm{C}$ for $2 \mathrm{~min}, 3$ cycles at $94^{\circ} \mathrm{C}$ for $30 \mathrm{~s}$, $47^{\circ} \mathrm{C}$ for $30 \mathrm{~s}$, and $68^{\circ} \mathrm{C}$ for $3 \mathrm{~min} ; 30$ cycles at $94^{\circ} \mathrm{C}$ for $30 \mathrm{~s}$, $58^{\circ} \mathrm{C}$ for $30 \mathrm{~s}$, and $68^{\circ} \mathrm{C}$ for $3 \mathrm{~min}$; followed by $15 \mathrm{~min}$ at $68^{\circ} \mathrm{C}$. Thermal cycling condition for amplifying the $3^{\prime}$ end region and other specific RT-PCR were as follows: $94^{\circ} \mathrm{C}$ for $2 \mathrm{~min}, 32$ cycles at $94^{\circ} \mathrm{C}$ for $30 \mathrm{~s}, 58^{\circ} \mathrm{C}$ for $30 \mathrm{~s}$, and $68^{\circ} \mathrm{C}$ for $3 \mathrm{~min}$ followed by $15 \mathrm{~min}$ at $68^{\circ} \mathrm{C}$. RT-PCR clones for both the $5^{\prime}$ and $3^{\prime}$ end regions in the correct orientation were selected for constructing the fulllength cDNA clones, which were cloned in the pGEM-T easy vector and sequenced by cycle sequencing using M13 universal primers and sequence-specific primers listed in Table 1. CEQ 2000 Dye Terminator Cycle Sequencing with Quick Start Kit (Beckman Coulter Inc., Fullerton, CA) and CEQ 8000 Genetic Analysis System were used for sequencing. Sequence analysis was performed using the DNA strider (CEA, France) and Vector NTI programs (Informaxinc, Frederick, MD).

In vitro transcription and inoculation. Full-length RNA1 and RNA2 cDNA clones were linearized with SalI and used as templates for in vitro transcription as previously described (12). After transcription, samples $(5 \mu \mathrm{l})$ of transcription reaction mixture were analyzed by electrophoresis on $1 \%$ agarose gel to assess yield and quality. The RNA transcripts $(100 \mu \mathrm{l})$ were used to inoculate fully expanded primary leaves of 1-week-old soybean seedlings by rub inoculation.

\section{RESULTS}

Molecular characterization of the partial diploid reassortant strain IL-Cb1 and derivative local lesion isolates. In a previous study (14), we showed, based on nucleic acid hybridization analysis, that strain IL-Cb1 is a partial diploid reassortant that is diploid for RNA1 and haploid for RNA2. The partial diploid status of strain IL-Cb1, which induces very severe symptoms on soybean, was confirmed in the present study by cDNA cloning and sequencing of its genomic RNAs. The results indicated that it contained at least two genetically distinct RNA1s belonging to subgroups I and II, but only one type of RNA2 (subgroup I). For brevity from hereon, the designation of subgroup affiliation (I or II) of the viral RNAs will be indicated in parenthesis immediately next to the individual RNAs. The complete nucleotide sequences of the genomic RNAs of strain IL-Cb1 were deposited in GenBank under accession nos. AY744931, AY744932, and AY744933 for RNA1(I), RNA1(II), and RNA2(I), respectively. Following passage through two consecutive single lesion transfers on $P$. vulgaris cv. Pinto, a total of 16 local lesion isolates were selected for further studies. Among the 16 local lesion (LL) isolates, 13 induced very severe symptoms on soybean comparable to the parental field isolate IL-Cb1. Two such severe isolates (LL3 and LL16) were selected for further analysis. Like the parental strain IL-Cb1, these severe isolates (LL3 and LL16) induced necrotic local lesions on the inoculated leaves (arrowheads; Fig. 1) and severe systemic mottling and blistering on noninoculated leaves (Fig. 1). Of the remaining three LL isolates (Fig. 1), one induced moderate symptoms (LL9) and two were mild isolates (LL1 and LL10).

Northern hybridization analysis showed that strain IL-Cb1 RNA1 hybridized to both subgroup I- and subgroup II-specific probes (Fig. 2B and $\mathrm{C}$; lane $\mathrm{Cb} 1$ ). Whereas a strong hybridization signal was observed with the subgroup II-specific probe, a weaker signal was obtained with the subgroup I probe. RNA1 from the mild local lesion isolates LL1 and LL10 hybridized only to subgroup II-specific probes. RT-PCR cloning and sequencing confirmed that only subgroup II RNA1 is present in these two mild isolates. These results are consistent with previous studies that indicated that subgroup II RNA1 is associated with mild symptoms $(12,13)$. The moderate isolate LL9, on the other hand, contained only subgroup I RNA1 (Fig. 2C and D). This was also confirmed by RT-PCR cloning and sequencing using the BPMV RNA1-specific primer pair F1 and R1-Rev1 (Table 1). Although the two severe local lesion isolates, LL3 and LL16, showed hybridization signals to only subgroup I RNA1 (Fig. 2B and C), RTPCR cloning and sequencing indicated that they contain both types of RNA1 (subgroups I and II) and that LL3 also contained intermolecular and intramolecular RNA1 recombinants (described below). 
Northern hybridization analysis using cloned cDNA probes specific for both subgroups I and II RNA2s showed that IL-Cb1 and its five local lesion isolates contained only subgroup I RNA2 (Fig. 2D and E). To further verify that the local lesion isolates are haploid for RNA2, genomic RNAs extracted from purified virions of the parental strain and its five local lesion isolate derivatives were used as templates for RT-PCR with the primer pair F1 and R1 (Table 1). This primer pair anneals, respectively, to strictly conserved terminal sequences at the $5^{\prime}$ and $3^{\prime}$ ends of BPMV genomic RNAs. The PCR products were cloned and more than 10 RNA2 cDNA clones for each of these isolates were sequenced. The RNA2 sequences for all five local lesion isolates were indistinguishable from the RNA2(I) sequence of the parental isolate IL-Cb1 (data not shown). Taken together, these results indicate that strain IL-Cb1 is a partial diploid reassortant, diploid for RNA1 and haploid for RNA2.

Isolation and characterization of recombinant RNA1 from BPMV strain IL-Cb1. cDNA cloning and sequencing of IL-Cb1 RNA1 indicated the presence of chimeric (clone IL-Cb1-210) and mosaic RNA1 recombinants (clone IL-Cb1-201) in addition to subgroups I and II RNA1s (Fig. 3). As mentioned earlier, intermolecular and intramolecular RNA1 recombinants (clones LL3-
B15 and LL3-119, respectively; Fig. 3) were identified in the severe local lesion isolate LL3. To determine whether the recombinant LL3-B15 occurs in the parental strain IL-Cb1 and whether it is the same as the recombinant IL-Cb1-210, RT-PCR cloning and sequencing were performed using several pairs of primers targeting different regions in the recombinant RNA1 (Fig. 3). Initially, two overlapping cDNA fragments were amplified from IL-Cb1 RNA using two pairs of primers corresponding to the $5^{\prime}$ end (primers F1 and R1-Rev-XhoI; Table 1 and Fig. 3) and the 3' end (primers Han-R1-For- $6^{\text {th }}$ (II) and R1-Rev1; Table 1 and Fig. 3) regions of the recombinant RNA1. Both the $5^{\prime}$ end $(3.0 \mathrm{kbp})$ and the $3^{\prime}$ end (3.5 kbp) fragments (Fig. 3, see horizontal lines immediately above and below construct LL3-B15) were cloned and sequenced. Sequence analysis confirmed that the recombinant LL3-B15 does indeed occur in strain IL-Cb1 and that it is the same as the chimeric recombinant IL-Cb1-201. In addition to the overlapping 3.0- and 3.5-kbp cDNA fragments described above, a $3.3-\mathrm{kbp}$ fragment that includes the recombination site and flanking sequences also was cloned and sequenced from LL3 virion RNA using primers HopSpeI-For (subgroup I-specific) and HanRev3400 (subgroup II-specific; Fig. 3, 3.3-kb overlapping fragment). Moreover, a $5.7 \mathrm{kbp}$ near full-length RT-PCR product corresponding to

TABLE 1. Primers used for reverse transcription-polymerase chain reaction (RT-PCR) cloning and sequencinga

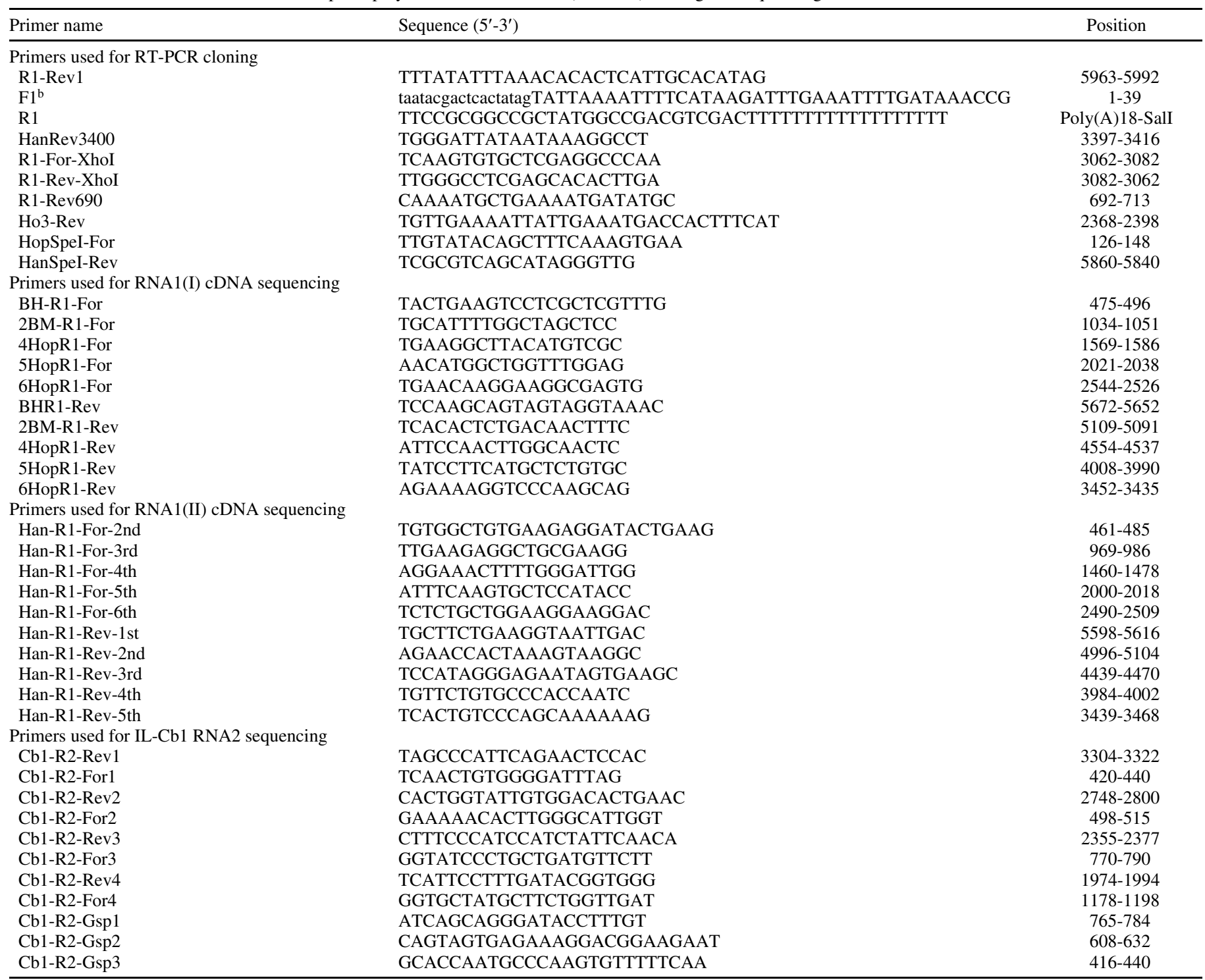

a The designations Han-R1 and Hop-R1 in the primers name refer to RNA1 (subgroup II) from strain Hancock (K-Ha1) and RNA1 (subgroup I) from strain Hopkins (K-Ho1), respectively.

${ }^{\mathrm{b}}$ The modified $\mathrm{T} 7$ promoter sequence is written in lowercase. 
the recombinant RNA1 was amplified from LL3 RNA using primers HopSpeI-For(I) and HanSpeI-Rev(II) (Fig. 3, 5.7-kb overlapping fragment). Cloning and sequencing of this RT-PCR product provided strong evidence that the full-length recombinant RNA1 exists in isolate LL3, even though at a low level. As a control for RT-PCR, RNA extracted from LL9 and LL10 virions, containing RNA1(I) and RNA1(II), respectively, were mixed together and used as templates for RT-PCR with primers HopSpeI-For(I) and Han-Rev3400(II), specific for subgroups I and II RNA1, respectively. No PCR products were generated in this control experiment (data not shown), indicating that the recombinants were derived from the viral RNA population and are not RT-PCR artifacts.

Symptoms induced by chimeric and mosaic recombinant RNA1 clones derived from strain IL-CB1 and its local lesion isolates. A mosaic RNA1 (IL-Cb1-201), resulting from double recombination events, was identified from strain IL-Cb1 by RTPCR using primers F1 and R1-Rev-XhoI (Fig. 3). A full-length cDNA clone of this mosaic RNA1 was infectious and induced mild symptoms on soybean (Fig. 1). The RNA1 deletion mutant LL3-119 was amplified from LL3 using primers F1 and R1-RevXhoI. Since this deletion mutant lacks part of the helicase gene, no further attempt was made to produce a full-length cDNA clone. When transcripts from the full-length infectious cDNA clone of the chimeric recombinant RNA1 (clone LL3-B15) were used to inoculate soybean seedlings, only mild symptoms were produced (Fig. 1).
Accumulation levels of recombinant and wild-type RNA1 in mixed infections. The recombinant RNA1, which was purified from soybean plants previously inoculated with transcripts derived from LL3-B15 RNA1 and IL-Cb1 RNA2 cDNAs, showed strong hybridization signals to both types of RNA1-specific probes (Fig. 2, lane 3-B15). The virion RNA isolated from strain IL-Cb1, on the other hand, showed weaker signals to the subgroup I RNA1 probe (Fig. 2; compare lanes 3-B15 and Cb1). Four cDNA fragments representing the $5^{\prime}$ and $3^{\prime}$ end regions of both types of RNA1 were generated by PCR using full-length cDNA clones of the two RNA1 subgroups as templates. Schematic representation of the two RNA1 subgroups and the four cDNA fragments, fragments $\mathrm{b}$ and $\mathrm{d}$ (subgroup I) and $\mathrm{c}$ and $\mathrm{e}$ (subgroup II), are shown in Figure 4F. Although hybridization results with fragment-based probes were similar to those prepared from full-length RNA1 cDNA, the recombinant LL3-B15 showed a unique profile. It hybridized to the RNA1(I) $5^{\prime}$ end probe (derived from fragment b) and the RNA1(II) $3^{\prime}$ end probe (derived from fragment e). However, it did not hybridize to the RNA1(II) 5' end probe (fragment c) nor to the RNA(I) 3' end probe (fragment $\mathrm{d}$ ). The finding that the recombinant LL3B15 RNA1 exhibited a strong hybridization signal to the probe (Fig. 4E), which represents the $3^{\prime}$ end region of subgroup II RNA1, whereas no signals were evident with LL3 RNA1 using the same probe, indicated that the accumulation level of the recombinant LL3-B15 was lower than can be detected in

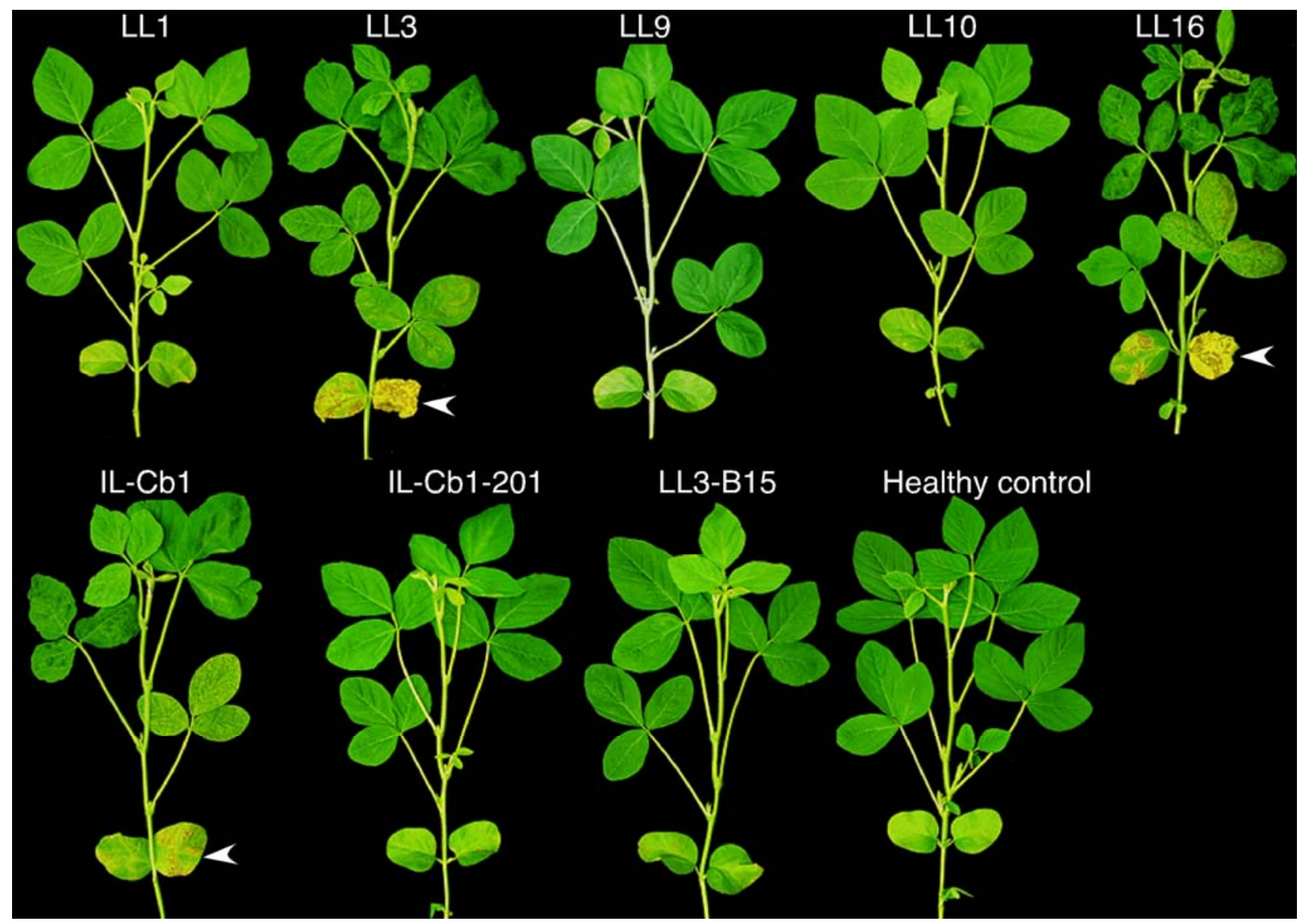

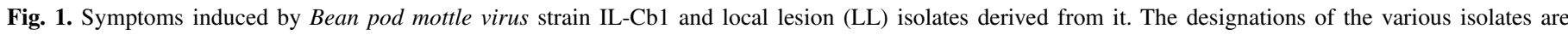

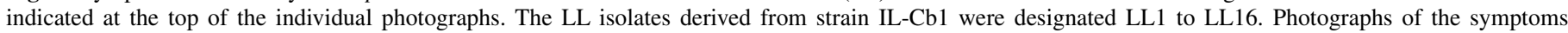

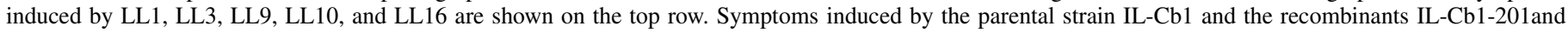



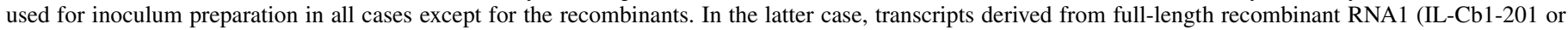

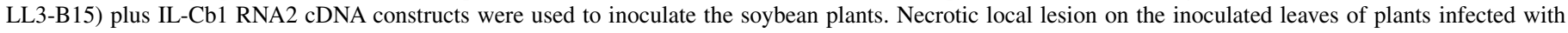
strain IL-Cb1 and the two severe LL derivatives (LL3 and LL16) are indicated by arrowheads. Photographs were taken 21 days postinoculation. 
mixed infections with wild-type RNA1s present in isolate LL3 (Fig. 4E).

Recovery of recombinant RNA1 from soybeans plants inoculated with transcripts derived from two genetically distinct cloned RNA1 cDNAs. The finding that the intermolecular RNA1 recombinant LL3-B15 (or IL-Cb1-210) occurs in strain IL-Cb1 and its single lesion derivative (LL3) prompted the question of whether a comparable recombinant RNA1 can be generated from mixed infections with transcripts from full-length cDNA clones derived from both types of RNA1. To address this question, soybean plants were inoculated with transcripts derived from cloned K-Ho1 RNA1(I) and K-Ha1 RNA1(II) cDNAs along with K-Ho1 RNA2(II) transcript. Progeny virus from transcript-inoculated, systemically infected plants was subjected to four serial passages in soybean. Purified virions were prepared from the fourth passage plants and virion RNA was used as a template for RTPCR cloning and sequencing. Using primers HopSpeI-For and HanRev3400 (Table 1), a single PCR product corresponding to the 3.3-kbp fragment (Fig. 3) was generated, gel purified, and sequenced. Sequence analysis showed that it was similar to LL3B15 and resulted from a recombination event between K-Ho1 RNA1(I) and K-Ha1 RNA1(II) (Fig. 5; HoHa recombinant). Sequence alignment suggested that the recombination region that contains the putative recombination site is AU-rich (81.8\%; Fig. 5 , boxed sequence) and that it is flanked downstream by another AU-rich region (75\%; Fig. 5, underlined). The short region of sequence identity (11 nucleotides) between the parental RNA1s (Fig. 5, boxed sequence) is proposed to facilitate precise recombination events.

\section{DISCUSSION}

The identification of natural recombination events between virus strains is important in considerations of virus evolution. Plant RNA virus recombination can occur between different virus species and the role of recombination in evolution has been con- firmed experimentally for luteoviruses, nepoviruses, bromoviruses, potyviruses, and cucumoviruses $(8,15,19,20,27,28)$. The present study provides the first report on recombination in a virus belonging to the genus Comovirus.

Previous studies on the genetic diversity of BPMV documented the occurrence in nature of two distinct subgroups of BPMV strains (subgroups I and II) as well as reassortants between these two subgroups $(12,13)$. Furthermore, evidence is presented herein and in our recent studies that some of the naturally occurring strains that induce very severe symptoms in soybean are partial diploid reassortants, i.e., they are diploid for RNA1 and haploid for RNA2 $(12,14)$. The occurrence of such partial diploids at relatively high frequency suggests that mixed infections with two distinct strains are also common. The isolation and characterization of intermolecular BPMV RNA1 recombinants provides undisputed evidence that two distinct BPMV strains may replicate in the same cells. The occurrence of recombinants and reassortants in the natural populations of BPMV and their roles in the emergence of new strains that induce different symptoms are of considerable significance to studies on BPMV evolution and epidemiology. Furthermore, such extensive diversity in BPMV genotypes should be a matter of great concern to plant pathologists and plant breeders who seek to screen soybean germplasm for BPMV resistance.

The finding that the recombinant RNA1 generated by infection with transcripts comprising a partial diploid pseudorecombinant is structurally similar to the naturally occurring recombinants suggests that the recombination region is a hot spot for recombinational events. Furthermore, the fact that three types of recombinants (mosaic, chimeric, and deletion) that were characterized in this study share similar recombination regions further supports the presence of a recombination hot spot. Moreover, sequence analysis showed that the recombination region has AU-rich sequences characteristic of recombination hot spots (Fig. 5). It is also interesting that the recombination hot spot is located in the helicase gene, which was previously shown to be a symptom severity determinant (12).

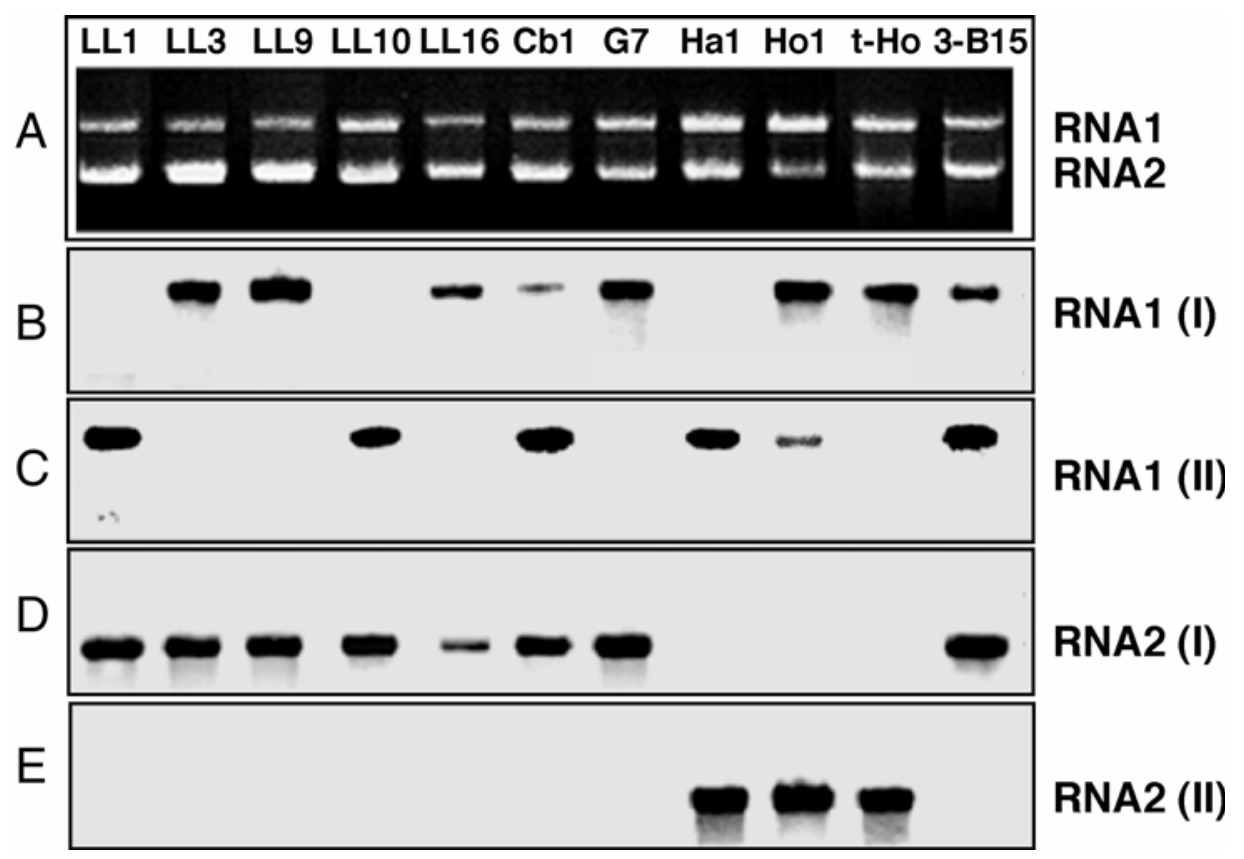

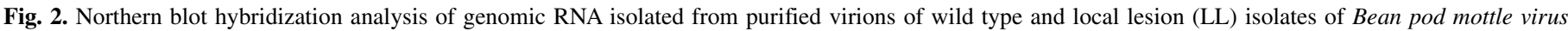

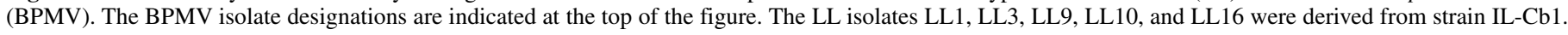

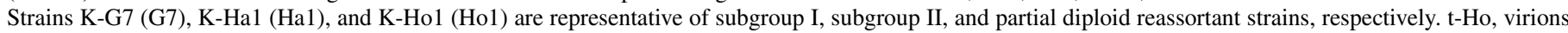

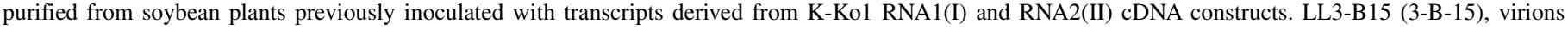

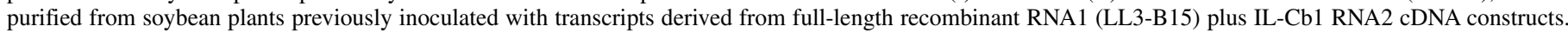

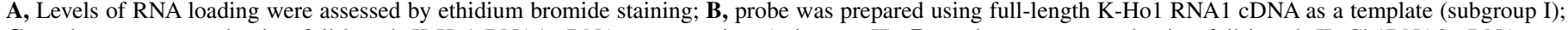

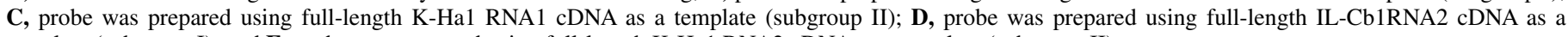
template (subgroup I); and E, probe was prepared using full-length K-Ha1 RNA2 cDNA as a template (subgroup II). 
Our results on the molecular characterization of the BPMV intermolecular RNA1 recombinants suggest that they belong to class 1 recombination, i.e., similarity-essential recombination, as defined by Nagy and Simon (21), and that they are precise recombinants. The presence of a short region of identical sequences between the parental molecules within the recombination region allows for the generation of precise recombinants (Fig. 5, boxed sequences). The AU-rich region downstream of the putative recombination site (Fig. 5) is proposed to serve as a signal for the viral replicase to pause due to the weak A-U base pairing between the growing nascent strand and the donor RNA template inside the replicase, and thus the possibility for template switch. The template-switching (copy-choice) mechanism, which entails that the viral RdRp switches templates during RNA synthesis, is probably the most accepted mechanism underlying viral RNA recombination. Following the switch from the donor to the acceptor RNA, the replicase is believed to resume RNA synthesis on the acceptor template, using the nascent RNA as a primer $(6,21)$.

It is of interest that all natural recombinants characterized so far have their $5^{\prime}$ end regions derived from subgroup I RNA1 and their $3^{\prime}$ end regions derived from subgroup II RNA1, suggesting that this genome arrangement is better adapted for survival in the host than the reverse arrangement. In this regard, the finding that the natural recombinants retain the C-terminal half of subgroup II helicase coding region is of considerable interest in view of the fact that the subgroup I-derived C-terminal half of the helicase coding region is a major determinant of enhanced symptom severity (12).

Subgroup II BPMV strains, which induce only mild symptoms on soybean, are the most widely occurring BPMV strains $(13,14)$, and thus are the most adapted to their hosts. The natural recombinants were apparently at a competitive disadvantage for replication and accumulation in the presence of wild-type RNA1 in mixed infections, as judged by northern hybridization analysis of virion RNA. The reason for this is not clear since the recombinant RNA1 accumulated to comparable levels of those of the wild-type RNA1 in separate infections involving the recombinant RNA1 or the wild-type RNA1 (Fig. 4). This suggests that encapsidation of the recombinant RNA1 and movement of the resultant virions occur as efficiently as the wild-type RNA1.

In summary, we have isolated and characterized at the molecular level naturally occurring BPMV RNA1 recombinants. The

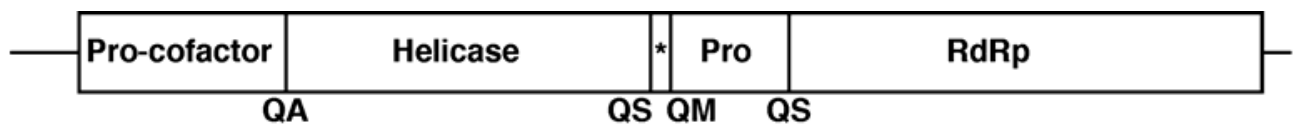

RNA1 (I)

IL-Cb1-201
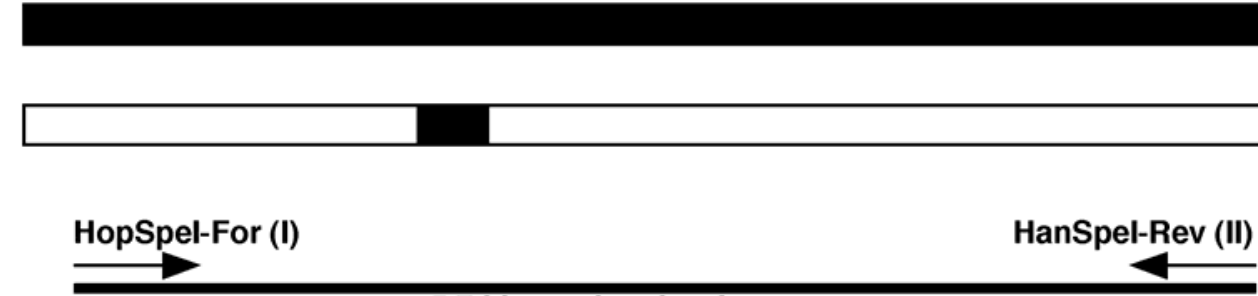

$5.7 \mathrm{~kb}$ overlapping fragment

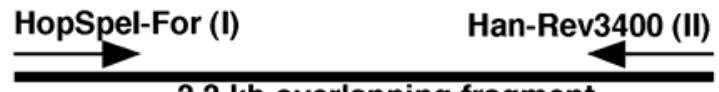

$3.3 \mathrm{~kb}$ overlapping fragment

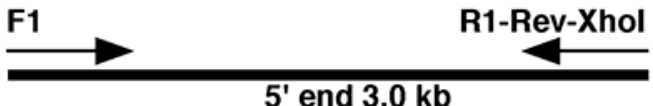

5 ' end $3.0 \mathrm{~kb}$

IL-Cb1-210

LL3-B15

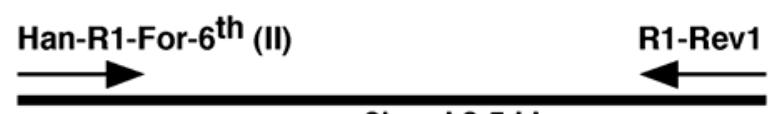

3 ' end $3.5 \mathrm{~kb}$

LL3-119

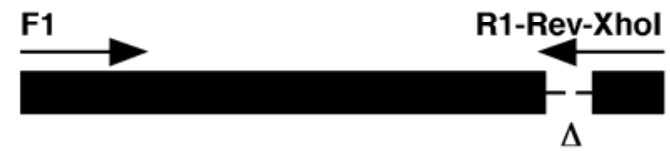

RNA1 (II)

Fig. 3. Schematic representation of the RNA1 cDNA clones derived from strain IL-Cb1 and its local lesion (LL) isolate LL3. A diagram of Bean pod mottle virus RNA1 genome organization is shown at the top. The relevant cDNA constructs of RNA1 subgroups I and II are shown as black and open rectangles at the top and bottom of the figure; IL-Cb1-201 is a mosaic recombinant RNA1 cDNA clone derived from strain IL-Cb1; IL-Cb1-210 is a chimeric RNA1 cDNA clone derived from strain IL-Cb1; LL3-B15 is a chimeric RNA1 cDNA clone derived from the LL isolate LL3 and is indistinguishable from clone IL-Cb1-210; and LL3-119 is a deletion recombinant RNA1 cDNA clone derived from the LL isolate LL3. The line drawings above the IL-Cb1-210 and LL3-B15 constructs represent the cDNA clones that were amplified by reverse transcription-polymerase chain reaction (RT-PCR) from these recombinant RNA1s. The lines drawings below the IL-Cb1210 and LL3-B15 constructs represent the cDNA clones that were amplified by RT-PCR from the 3' end of these recombinant RNA1s. Subgroup-specific primers are indicated by placing the subgroup designation between parentheses next to the primer's name. Primers without subgroup designations represent strictly conserved sequences between the two subgroups. 
recombination region, which occurs in the helicase coding region, is proposed to comprise a hot spot for recombination. The intermolecular recombinant RNA1 retained the type II C-terminal region of the helicase gene, and thus induced mild symptoms on soybean comparable to those induced by the subgroup II parental strain. Although the recombinant RNA1 was less competitive for replication and accumulation in the presence of wild-type RNA1, occasional successful transmission of recombinant BPMV by the beetle vector would allow the generation of mild strains from the parental severe strains. Thus, recombination events may conceivably provide a mechanism to counterbalance the devastating effects of the severe BPMV strains on host survival, and consequently virus survival, via the generation of mild strains that are better adapted to their host.

\section{ACKNOWLEDGMENTS}

This work was funded in part by grants (to S. A. Ghabrial) from the Kentucky Soybean Promotion Board and the North Central Soybean Research Program. This paper (no. 06-12-045) is published with the approval of the Director of the Kentucky Agricultural Experiment Station. We thank W. Havens for technical support and A. Crume for greenhouse care.

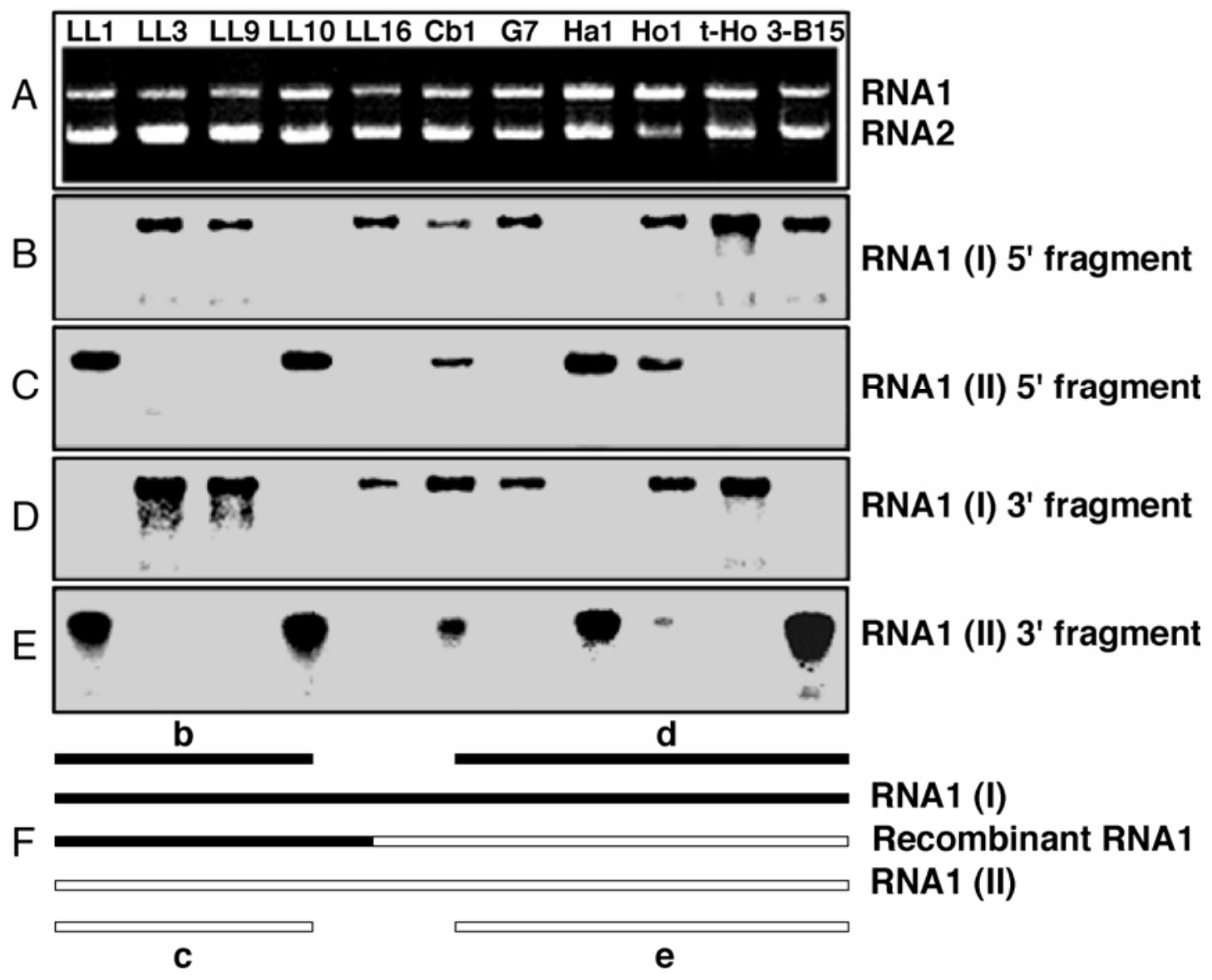

Fig. 4. Northern blot hybridization analysis of genomic RNA isolated from purified virions of different Bean pod mottle virus strains and local lesion isolates derived from strain IL-Cb1. Figure 2 provides virus strain and local isolate designations. A, Levels of RNA loading were assessed by ethidium bromide staining; $\mathbf{B}$, probe was prepared from a 2-kbp polymerase chain reaction (PCR) product $\mathbf{b}$ derived from the $5^{\prime}$ end region of K-Ho1 RNA1(I) cDNA; C, probe was prepared from a 2-kbp PCR product $\mathbf{c}$ derived from the $5^{\prime}$ end region of K-Ha1 RNA1(II) cDNA; D, probe was prepared from a 3-kbp PCR product d derived from of the 3' end region of K-Ho1 RNA1(I) cDNA; E, probe was prepared from a 3-kbp PCR product e derived from of the 3' end region of K-Ha1 RNA1(II) cDNA; and $\mathbf{F}$, schematic representation of the cDNA fragments $(\mathbf{b}, \mathbf{c}, \mathbf{d}$, and e) used for probe preparation. Black rectangle represents subgroup I RNA1 and open rectangle represents subgroup II RNA1. A diagram of the chimeric recombinant LL3-B15 (recombinant RNA1) is drawn in the center between the diagrams of subgroup I and II RNA1s.

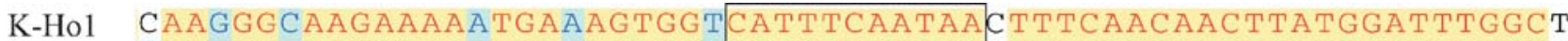 LL9 TAAGGGCAAGAAAAATAAAGTGGTCATTTCAATAACTTTCAACAACTTATGGATTTGGCT LL3-B15 TAAGGGCAAGAAAAATGAAATGGTCATTTCAATAATTTTCAACAACTTATGGATTTGGCA HoHa CAAGgGCAAGAAAATGAAatgGTCATTTCAATAATTTCAACAACTTATGGATTGGCA K-Hal tAaAgGCAAGAAAAgTGAGAgTGGCCATTTCAATAATTTCAACAACTTATGGATTTGGCA LL10 TAAAGGTAGAAAATGAGAGTGCCATTTCAATATTTTCAACAACTTATGGATTTGGCA}

Fig. 5. Multiple alignment of the nucleotide sequences of a fragment containing the probable recombination region in six different Bean pod mottle virus RNA1s (nucleotide positions 2353 to 2413). K-Ho1, RNA1(I) from strain K-Ho1; LL9, RNA1(I) from local lesion isolate 9 derived from strain IL-Cb1; LL3-B15, intermolecular recombinant RNA1 isolated from LL3 (local lesion isolate 3 derived from strain IL-Cb1); HoHa, intermolecular recombinant RNA1 isolated from soybean plants previously inoculated with a partial diploid pseudorecombinant consisting of K-Ho1 RNA1(I), K-Ha1 RNA1(II), and K-Ho1 RNA2 (II); K-Ha1, RNA1(II) from strain K-Ha1; and LL10, RNA1(II) from local lesion isolate 10 derived from strain IL-Cb1. The potential recombination region that contains the putative recombination site is boxed. The AU-rich region ( $75 \% \mathrm{AU})$ downstream of the recombination site is underlined. 


\section{LITERATURE CITED}

1. Allison, R. F., Thompson, C., and Ahlquist, P. 1990. Regeneration of a functional RNA virus genome by recombination between deletion mutants and requirement for cowpea chlorotic mottle virus $3 \mathrm{a}$ and coat genes for systemic infection. Proc. Natl. Acad. Sci. USA 87:1820-1824.

2. Bousalem, M., Douzery, E., and Fargette, D. 2000. High genetic diversity, distant phylogenetic relationships and intraspecies recombination events among natural populations of yam mosaic virus: A contribution to understanding potyvirus evolution. J. Gen. Virol. 81:243-255.

3. Bujarski, J. J., and Kaesberg, P. 1986. Genetic recombination between RNA components of a multipartite plant virus. Nature 321:528-531.

4. Cascone, P. J., Carpenter, C. D., Li, X. H., and Simon, A. E. 1990. Recombination between satellite RNAs of turnip crinkle virus. EMBO J. 9:1709-1715.

5. Chen, Y. K., Goldbach, R., and Prins, M. 2002. Inter- and intramolecular recombinations in the cucumber mosaic virus genome related to adaptation to alstroemeria. J. Virol. 76:4119-4124.

6. Cheng, C. P., and Nagy, P. D. 2003. Mechanism of RNA recombination in carmo- and tombusviruses: Evidence for template switching by the RNAdependent RNA polymerase in vitro. J. Virol. 77:12033-12047.

7. Di, R., Hu, C.-C., and Ghabrial, S. A. 1999. Complete nucleotide sequence of bean pod mottle virus RNA1: Sequence comparisons and evolutionary relationships to other comoviruses. Virus Genes 18:129-137.

8. Fernandez-Cuartero, B., Burgyan, J., Aranda, M. A., Salanki, K., Moriones, E., and Garcia-Arenal, F. 1994. Increase in the relative fitness of a plant virus RNA associated with its recombinant nature. Virology 203:373-377.

9. Ghabrial, S. A., Pickard, C. M., and Stuckey, R. E. 1977. Identification and distribution of virus diseases of soybean in Kentucky. Plant Dis. Rep. 61:690-694.

10. Gibbs, A. 1999. Evolution and origins of tobamoviruses. Phil. Trans. R. Soc. Lond. B 354:593-602.

11. Glasa, M., Marie-Jeanne, V., Labonne, G., Subr, Z., Kudela, O., and Quiot, J.-B. 2002. A natural population of recombinant Plum pox virus is viable and competitive under field conditions. Eur. J. Plant Pathol. 108:843-853.

12. Gu, H., and Ghabrial, S. A. 2005. The Bean pod mottle virus proteinase cofactor and putative helicase are symptom severity determinants. Virology 333:271-283.

13. Gu, H., Clark, A. J., de Sa, P. B., Pfeiffer, T. W., Tolin, S., and Ghabrial, S. A. 2002. Diversity among isolates of Bean pod mottle virus. Phytopathology 92:446-452.

14. Gu, H., Zhang, C., and Ghabrial, S. A. 2007. Novel naturally occurring Bean pod mottle virus reassortants with mixed heterologous RNA1 genomes. Phytopathology 97:79-86.
15. Le Gall, O., Candresse, T., and Dunez, J. 1995. Transfer of the 3 ' nontranslated region of grapevine chrome mosaic virus RNA-1 by recombination to tomato black ring virus RNA-2 in pseudorecombinant isolates. J. Gen. Virol. 76:1285-1289.

16. Le Gall, O., Iwanami, T., Karasev, A. V., Jones, T., Lehto, K., Sanfaçon, H., Wellink, J., Wetzel, T., and Yoshikawa, N. 2005. Comoviridae. Pages 807-818 in: Virus Taxonomy, 8th Report of the International Committee on Taxonomy of Viruses. C. M. Fauquet, M. A. Mayo, J. Maniloff, U. Desselberger, and L. A. Ball, eds. Elsevier/Academic Press, London.

17. Lomonossoff, G. P., and Ghabrial, S. A. 2001. Comoviruses. Pages 239242 in: Encyclopedia of Plant Pathology, Vol. 1. O. C. Maloy and T. D. Murray, eds. John Wiley and Sons, New York.

18. MacFarlane, S. A., Shanks, M., Davies, J. W., Zlotnick, A., and Lomonossoff, G. P. 1991. Analysis of the nucleotide sequence of bean pod mottle virus middle component RNA. Virology 183:405-409.

19. Miller, W. A., Dineshkumar, S. P., and Paul, C. P. 1995. Luteovirus gene expression. Crit. Rev. Plant Sci. 14:179-211.

20. Moonan, F., Molina, J., and Mirkov, T. E. 2000. Sugarcane yellow leaf virus: An emerging virus that has evolved by recombination between luteoviral and poleroviral ancestors. Virology 269:156-171.

21. Nagy, P. D., and Simon, A. E. 1997. New insights into the mechanisms of RNA recombination. Virology 235:1-9.

22. Peden, K. W. C., and Symons, R. H. 1973. Cucumber mosaic virus contains a functionally divided genome. Virology 155:487-492.

23. Roossinck, M. J. 1997. Mechanisms of plant virus evolution. Annu. Rev. Phytopathol. 35:191-209.

24. Sambrook, J., and Russell, D. W. 2001. Molecular Cloning: A Laboratory Manual. 3rd ed. Cold Spring Harbor Laboratory, Cold Spring Harbor, NY.

25. Smith, G. R., Borg, Z., Lockhart, B. E., Braithwaite, K. S., and Gibbs, M. J. 2000. Sugarcane yellow leaf virus, a novel member of the Luteoviridae that probably arose by inter-species recombination. J. Gen. Virol. 81:1865-1869.

26. Tomimura, K., Gibbs, A. J., Jenner, C. E., Walsh, J. A., and Ohshima, K. 2003. The phylogeny of turnip mosaic virus, comparisons of 38 genomic sequences reveal a Eurasian origin and a recent 'emergence' in east Asia. Mol. Ecol. 12:2099-2111.

27. Van der Kuyl, A. C., Neeleman, L., and Bol, J. F. 1991. Complementation and recombination between alfalfa mosaic virus RNA3 mutants in tobacco plants. Virology 183:731-738.

28. Varrelmann, M., Palkovics, L., and Maiss, E. 2000. Transgenic or plant expression vector-mediated recombination of Plum pox virus. J. Virol. 74:7462-7469.

29. White, K. A., and Morris, T. J. 1994. Recombination between defective tombusvirus RNAs generates functional hybrid genomes. Proc. Natl. Acad. Sci. USA 91:3642-3646. 